\title{
Activismos no violentos bajo dictaduras militares en Argentina y Chile: el Servicio de Paz y Justicia, 1974-1983
}

\author{
por María Soledad Catoggio
}

Abstract. - The purpose of this paper is to analyze the emergence and evolution of Latin American nonviolent movements in the different scales of global action, regional and national. Focusing on the case of the SERPAJ, we are dedicated specifically to analyze the passage of a defensive strategy to address human rights to physical violence by the repressive actions of the state to the formation of protest movements. These ones, defined by the methodology of "non-violence" were crucial to building an ethical and political lobbying that would pave the way to democracies. To do this, they combined in a particular way a methodology to process the political suffering with the denunciation of human rights violations. The success is based on a fundamentally emotional and ascetic appeal, effective to put on hold the ideological conflicts of the past.

\section{Introducción}

Los regímenes militares inaugurados en los años setenta en Argentina y Chile se caracterizaron por ser, en ese orden, los más cruentos del Cono Sur en materia de violaciones a los derechos humanos. Esta realidad cambió el eje de las discusiones en torno a la violencia política, de las cuales habían participado activamente diversos sectores del catolicismo latinoamericano. Durante la década del sesenta, la decepción con las experiencias desarrollistas, que no trajeron consigo el propugnado desarrollo, dejó paso violencia política como forma legítima para impulsar el cambio revolucionario. El vocabulario político-religioso reemplazó el concepto de desarrollo por el de liberación. La nueva terminología buscaba destacar el carácter estructural y conflictivo que caracterizaba a la realidad latinoamericana. En este contexto, tuvo lugar la inserción de muchos cristianos en los 
procesos revolucionarios del continente haciendo suya la "causa de las mayorías oprimidas". ${ }^{1}$

El clima triunfalista que impuso la Revolución Cubana en la región fue interrumpido por el ciclo represivo abierto con las dictaduras. La violencia política dejó de ser el eje de los foros de debate para instalar la urgencia de atender a las experiencias de sufrimiento de las víctimas de la violencia física impartida desde el accionar represivo del Estado. Para hacer frente a estas situaciones se fueron conformando los primeros organismos de derechos humanos en uno y otro caso. Aunque con marcadas diferencias, en ambos contextos nacionales nacieron como estrategias defensivas frente a la demanda de las víctimas y sus allegados y fueron emprendidas y/o engrosadas por actores y recursos provenientes del mundo religioso. A comienzos de los años ochenta cobraron visibilidad e importancia diversos movimientos de protesta que hicieron propia la bandera de la "no violencia" como formas de impugnación a las dictaduras. Traían consigo una nueva fórmula que prometía transformar las realidades sufrientes en alternativas liberadoras. Entre ellos, se destacó en América Latina el Servicio de Paz y Justicia (SERPAJ) que existía desde mediados de la década del setenta. Hacia fines de esa década, el SERPAJ creó filiales nacionales en ambos países y nutrió y/o acompañó diversas experiencias que ganaron autonomía propia, como fueron las Madres de Plaza de Mayo, en Argentina, y el Movimiento Contra la Tortura Sebastián Acevedo, en Chile.

En este contexto, la propuesta de este trabajo es analizar el surgimiento y la evolución de los no violentos latinoamericanos. A partir del caso del SERPAJ, nos detendremos específicamente en el análisis del pasaje de una estrategia defensiva de derechos humanos para hacer frente a la violencia física desplegada por el accionar represivo del Estado a la conformación de movimientos de protesta, definidos por la metodología de la "no violencia" que fueron decisivos para construir una interpelación ético-política que allanara el camino a las democracias.

\section{El acontecimiento fundante: "todos somos hijos de Medellín"}

El triunfo de la Revolución Cubana en el continente y los procesos de descolonización en el Tercer Mundo dotaron de un renovado marco de legitimidad a la violencia política como vía para la transformación social. La idea de vanguardia y la teoría del foco hacían posible acelerar las condicio-

1 Cfr. Michael Löwy, Guerra de Dioses. Religión y política en América Latina, Siglo XXI (México 1999), pp. 47-178. 
nes revolucionarias: la lucha revolucionaria misma generaría la conciencia para sí, sin necesidad de esperar a que las condiciones objetivas marcaran el tiempo de la revolución. En este contexto, sectores significativos del catolicismo acompañaron - e, incluso, alentaron - este clima social y político a partir de las definiciones plasmadas en la II Conferencia General del Episcopado Latinoamericano, reunido en Medellín, Colombia, en 1968. Allí, haciéndose eco de la encíclica Populorum Progressio, de 1967, recuperaban la doctrina católica sobre la legítima defensa ante la tiranía. En este marco, América Latina, definida por algunos sectores del clero como un "continente de violencia", una violencia estructural e injusta, se convertía en un escenario propio para la emergencia de otra violencia, temporaria y redimible: la "violencia justa de los oprimidos". ${ }^{2}$ De manera extendida, diversos sectores del catolicismo leyeron en este documento un llamado a los cristianos a despertar la conciencia de los oprimidos. Tuvo lugar entonces un proceso de politización de la vieja "cuestión social" que, siguiendo a la encíclica Rerum Novarum, había movilizado al catolicismo desde principios de siglo, en la búsqueda de integrar a los marcos de la nación a aquellos marginados por el modelo económico y político liberal, entonces en boga en la región. Bajo la consigna de la "opción por los pobres", así formulada tres años más tarde por el teólogo Gustavo Gutiérrez, lo que cambió no fue el compromiso con los pobres, sino el modo que se explicaba la pobreza y el papel que se promovía para los pobres en la iglesia, la sociedad y la política. ${ }^{3}$ Desde esta perspectiva, los pobres eran concebidos como sujetos de la transformación social y política, dotados de un capital propio: una percepción privilegiada de la realidad a partir de su misma situación de pobreza, que transformaba la situación de desposesión material en un capital simbólico. ${ }^{4}$ Para los católicos de entonces "optar por los pobres" contemplaba un amplio arco de posibilidades. En la práctica coexistieron diversos modelos de transformación social: cada uno de ellos definía un ámbito de acción privilegiado (la fábrica, la universidad, la villa, la comunidad, la cooperativa rural) y apostaba a un sujeto revolucionario (los trabajadores, los jóvenes, los indígenas, los pobres). Entre el clero, solo unos pocos, emu-

2 Carta del Movimiento de Sacerdotes para el Tercer Mundo enviada a Pablo VI y a los obispos reunidos en Medellín, junio de 1968, citado en Luis I. García Conde/Lidia González, Monseñor Jerónimo Podestá. La revolución en la Iglesia (Buenos Aires 2000), p. 158-163.

3 Daniel Levine, Voces populares en el catolicismo latinoamericano (Lima 1996), pp. 91 y 94 .

4 María Soledad Catoggio, “Católicos en el 'mundo de los pobres'. Imaginarios y sentidos frente a la situación represiva durante la última dictadura militar argentina, 19761983": Elizabeth Judd/Fortunato Mallimaci (eds.), Cristianismos en América Latina. Tiempo presente, historias y memorias (Buenos Aires 2013), p. 249. 
lando la figura de Camilo Torres, encontraron en la lucha armada el camino necesario para el cambio. Más importancia tuvo, sin duda, su rol en su carácter formativo de amplios sectores juveniles que siguieron el camino de las armas. La vía insurreccional formó parte de la "violencia popular legítima", alentada entre el laicado por sectores significativos del clero. ${ }^{5}$

A tono con el clima epocal, la lucha por el signo de la "revolución" como medio para la transformación de realidades institucionalmente injustas fue aceptada por aquellos católicos que apostaron por el camino de la llamada "no violencia activa". Incluso, llegaron a confluir en esa búsqueda de cómo instrumentar el cambio.

"Llegamos a Bogotá (Colombia) en febrero de 1962, sin conocer a nadie. En el aeropuerto le pedimos a un sacerdote que nos llevara a la ciudad. Era un sacerdote brasileño que trabajaba en el CELAM (Conferencia Episcopal Latinoamericana), que por entonces era una oficina sin importancia. Fue él quien nos dijo que en Colombia había un sacerdote joven, muy comprometido por la justicia, con quien sería muy importante que nos encontráramos. Ese sacerdote se llamaba Camilo Torres [...] Nunca olvidaremos - anotan Jean y Hildegard en su relato - la noche que pasamos conversando con él. Fue Camilo quien nos ayudó a comprender el conjunto de las sociedades injustas y opresoras, tanto de las sociedades como de las iglesias, y el sufrimiento del pueblo [...] Su conclusión fue: en fin, no veo otra posibilidad que hacer la revolución con las armas". ${ }^{6}$

Esta convergencia entre los fundadores de dos concepciones del cambio social (la lucha armada y la vía no violenta), que con el tiempo llegarán a estar en las antípodas, no era casual en aquellos años. En esa época llegaron a formar parte, incluso, de un mismo repertorio de contestación. Baste recordar al joven Fidel Castro que, tras dirigir el asalto armado al cuartel de la Moncada en 1953, llevaría adelante una huelga de hambre en la cárcel, con tanta repercusión que forzaría su liberación. En efecto, la dictadura se vio entonces obligada a liberarlo con el cometido de acabar con lo que ya era: el símbolo de la resistencia. En ese contexto, ambas formas de protesta,

5 Cfr. Luis Miguel Donatello, Catolicismo y Montoneros. Religión, política y desencanto (Buenos Aires 2010). Esta demanda del clero hacia el laicado puede rastrearse en los mismos borradores de los Documentos Finales de Medellín. El trabajo de Bonnin documenta la operación de censura realizada por el clero con respecto a la escritura original del documento sobre (y de) los laicos en Medellín, quitando las demandas eclesiásticas y reemplazándolas por otras, de índole política, que no se encontraban en la versión original del texto. Cfr. Juan Eduardo Bonnin, Discurso político y discurso religioso en América Latina. Leyendo los borradores de Medellín (1968) (Buenos Aires 2013).

6 Testimonio de Jean e Hildegard Goss Mayr en Carlos Muñoz, “¿Una alternativa revolucionaria?": Reseña Histórica del SERPAJ-AL 6-7 (1986). 
el asalto a los cuarteles y la huelga de hambre, eran acciones que estaban orientadas a producir un acto simbólico que despertara la conciencia y la insurrección de las masas. Esta búsqueda por el significado, común en los inicios de distintas organizaciones armadas en la región se irá diluyendo a medida que gane terreno la lógica bélica en los procesos revolucionarios de la región.

En el caso de los no violentos latinoamericanos, la aceptación de la vía revolucionaria se plasmaría en el tiempo en hechos concretos como la justificación que estos movimientos hicieron de la revolución nicaragüense, a fines de los años setenta, o la aceptación de militantes de organizaciones armadas entre las filas de sus movimientos, como sucedió con el Movimiento Contra la Tortura Sebastián Acevedo, a comienzos de los años ochenta en Chile. "Tolerábamos que participaran en el Movimiento miristas o otros que aún profesaban la violencia en otros contextos". ${ }^{7}$

La importancia de los Documentos Finales de la II Conferencia General del Episcopado Latinoamericano, reunida en Medellín, fue la de constituirse en hito fundante de una tradición latinoamericana y contestataria. Tal como lo ha formulado Bonnin, el mismo discurso jerárquico e institucional de la Iglesia Católica se impregnó entonces de una retórica "revolucionaria" marcadamente epocal. Esta característica hizo posible que estos textos devinieran en un "discurso fundador" para grupos político-religiosos de un amplio espectro y no siempre conciliables: desde sectores eclesiásticos, como la Teología de la Liberación o las Comunidades Eclesiales de Base hasta organizaciones armadas sin una identidad explícitamente confesional, como Montoneros o el Ejército Sandinista de Liberación. ${ }^{8}$ Los Documentos finales de Medellín fueron el primer ejemplar - con amplia difusión - del magisterio posconciliar latinoamericano y, por ello, irrenunciable incluso para aquellos que, interpelados por la construcción de una identidad contestataria y latinoamericanista, pretendían fundar su acción en las antípodas de la violencia legítima.

En esta sintonía, Adolfo Pérez Esquivel, coordinador latinoamericano del Servicio de Paz y Justicia desde 1974, definía:

7 José Aldunate, "El Movimiento contra la Tortura Sebastián Acevedo. Una relación complementaria": Hernán Vidal (ed.), El Movimiento contra la tortura "Sebastián Acevedo“. Derechos humanos y la producción de símbolos nacionales bajo el fascismo chileno (Santiago de Chile 2002), p. 10.

8 Bonnin, "Discurso" (nota 5), p. 7. 
"Todos nosotros somos hijos de Medellín [...] todos los esfuerzos de renovación de vida cristiana y todas las iniciativas en la lucha por la justicia encuentran su fundamento y su justificación en las conclusiones del encuentro de Medellín de 1968. Los no-violentos latinoamericanos también han salido de él". ${ }^{9}$

Pese a esta declaración de principios, los movimientos de no violencia aquí analizados surgen, sintomáticamente, de otro Medellín, convocado por iglesias ecuménicas y movimientos de paz, en 1974.

\section{El otro Medellín: la fundación del Servicio de Paz y Justicia Latinoamericano}

Los movimientos de no violencia activa llegan a América Latina en los años sesenta, pero tienen un origen más remoto tanto en Europa como en Estados Unidos. En esos años llegó a la región el matrimonio de Jean Goss y Hildegard Goss-Mayr, ambos referentes del Internacional Fellowship of Reconciliation (IFOR), para difundir sus ideas de no violencia. Este organismo había sido creado en Europa, a comienzos de la Primera Guerra Mundial, por dos cristianos, Henry Hodgkin (un cuáquero inglés) y Friedrich Siegmund-Schultze (un luterano alemán) y llegado a los Estados Unidos en 1917, constituyéndose en portavoz de los cristianos en contra de la guerra. Uno de los logros que el organismo celebraría como emblema sería, durante su participación en el Concilio Vaticano II, el de la condena de la guerra en las encíclicas conciliares (Gaudium et Spes 77).$^{10} \mathrm{~A}$ fines de los años sesenta Jean Goss y Hildegard Goss-Mayr hicieron su primera visita a Chile y dieron una conferencia sobre la alternativa de la no violencia en la Universidad Católica de Valparaíso. Al mismo tiempo, Earl Smith, pastor metodista, referente de la sección norteamericana, American Fellowship of Reconciliation (AFOR), organizó en Montevideo, en 1966, la primera consulta internacional, llamada La no violencia cristiana en la revolución latinoamericana. Allí se reunieron representantes de nueve países de América Latina, un delegado de Martin Luther King e invitados de Europa y Estados Unidos para debatir acerca de la implementación de la lucha no violenta en las revoluciones latinoamericanas. Entre ellos, se encontraban destacadas

9 Adolfo Pérez Esquivel, Lucha no violenta por la paz. Testimonios en América Latina (Bilbao 1983), p. 16.

${ }^{10}$ Fernando Aliaga Rojas, "La no-violencia durante la dictadura", p. 8, en línea: http:// serpajchile.cl/inicio/wp-content/uploads/2014/06/LA-NO-VIOLENCIA-DURAN-

TE-LA-DICTADURA.pdf [19-03-2015]. 
figuras como Giuseppe Lanza del Vasto (Comunidad del Arca), Danilo Dorci (Movimiento no violento de Sicilia), los intelectuales latinoamericanos, Sergio Bagú y Carlos Quijano y los pastores Hiber Conteris y Emilio Castro. ${ }^{11}$

Estas circulaciones internacionales crearon el clima propicio para la celebración en 1971 de la primera asamblea continental del entonces llamado Servicio para la Acción Liberadora (acción no violenta), en Alajuela, Costa Rica, con coordinación de Earl Smith y la participación del matrimonio Goss. La asistencia al encuentro, del obispo brasileño Hélder Cámara, arzobispo de Olinda y Recife, que a partir de entonces acogió la pastoral de la no violencia activa en su diócesis, dio inicio a un proceso de arraigo local de estas ideas. Sin embargo, estos esfuerzos por instalar la consigna de la no violencia en la región distaban de concretarse en otros países, como Argentina y Chile, donde se imponía la adopción (o la adhesión) a lucha armada como fórmula sine qua non del compromiso político.

“"Al principio, y por mucho tiempo, fuimos un grupo muy chico donde estaban mi papá, algunos amigos míos y otros compañeros míos de la escuela', recuerda Leonardo, el hijo mayor de Adolfo. El grupo formaba parte de la Comunidad del Arca, influenciado por Lanza del Vasto. Durante varios años se llamó Servicio para la Acción Liberadora en América Latina (orientación no violenta). En el océano de siglas que comenzaban a aparecer en el efervescente escenario político de la Argentina de mediados de los años 60, el nombre era uno más; pero seguramente llamaba la atención por ese agregado entre paréntesis casi como si pidiera disculpas. En las discusiones de aquellos años la idea de la no violencia se vinculaba más con el descompromiso, a la búsqueda de caminos individuales más que sociales [...] Los sectores que impulsaban la lucha armada visualizaban a ésta como el mayor nivel de compromiso". ${ }^{12}$

"Uno de los integrantes activos de estos hechos y gran líder de la No Violencia Activa a nivel mundial, Jean Goss, visitó Valparaíso en el año 1969. Habló en la Universidad Católica de Valparaíso, sin tener un gran eco ya que la realidad fuertemente tensionada por los grupos paramilitares de derecha y de izquierda no dejaban espacio para su propuesta. El matrimonio formado por Jean Goss e Hildegard Mayer (sic) volvería al país más tarde, apoyando la formación del SERPAJ Chile". ${ }^{13}$

${ }^{11}$ María Teresa Piñero, "Iglesias protestantes y terrorismo de Estado": Jornadas de trabajo sobre exilios políticos del Cono Sur en el siglo XX (2012), p. 16; Rojas, "No-violencia" (nota 10), p. 11; Muñoz, "Alternativa“" (nota 6), p. 9.

${ }^{12}$ Leonardo Pérez Esquivel, citado en Luis Bruchstein, "Los aportes del Serpaj al Movimiento de Derechos Humanos en Argentina. Por el camino de la no violencia": Puentes 2:6 (2002), p.2.

${ }^{13}$ Rojas, "No-violencia" (nota 10), p. 9. 
En 1974, la ciudad de Medellín (Colombia) volvió a ser sede de un hito fundacional (aunque de menor escala). En esta ocasión un grupo de obispos, pastores, religiosos, laicos y referentes de movimientos de base dieron nacimiento al Servicio de Paz y Justicia, cuyos ejes de trabajo se definieron como

“a) el compromiso con los oprimidos en la búsqueda del respeto integral a los derechos humanos, en orden a la construcción de una sociedad más justa y más fraterna; b) el vivir el Evangelio junto a los pobres, y c) la orientación no violenta". ${ }^{14}$

El Servicio, que contaba entonces con setenta y cinco delegados de veintidós países, nombró al argentino Adolfo Pérez Esquivel como secretario para el subcontinente. Para que esta constitución tuviera efecto fue decisiva la participación de un grupo de obispos católicos y protestantes, emblemáticos por su impronta liberacionista, entre los cuales se destacaban los obispos de Brasil, Hélder Cámara, Francisco Fragoso y el cardenal Paulo Evaristo Arns; el obispo de Ecuador, Leonidas Proaño; y los protestantes, Federico Pagura y Carlos Gatinoni. ${ }^{15}$

Medellín era entonces escenario de nuevas voces dentro del catolicismo que, sin borrar su marca de origen, contestataria y latinoamericanista, buscaban legitimar otros cursos de acción para transformar la violencia institucional e injusta del continente.

A este acto fundacional buscaron sumar un apoyo eclesiástico entre las jerarquías católicas, convocando a un grupo de obispos latinoamericanos, muchos de los cuales habían participado de la II CELAM en Medellín.

En 1977, bajo el lema "La no violencia evangélica, fuerza de liberación" se reunieron en Bogotá (Colombia) una veintena de obispos, sacerdotes y militantes católicos de nueve países de América Latina (Brasil, Bolivia, Perú, Venezuela, El Salvador, Chile, Ecuador y Panamá). No casualmente, en Bogotá estaba localizado el CELAM. Su fundación en 1955 había facilitado un proceso de integración efectiva entre obispos latinoamericanos, que entablaron vínculos y afinidades regionales basadas más en relaciones interpersonales que institucionales. ${ }^{16}$ En buena medida la red de obispos, sacerdotes y militantes cristianos no violentos era una expresión de ello. Al mismo tiempo, gracias a estas mismas redes los no violentos hacían uso de las estructuras eclesiásticas latinoamericanas existentes para dar legitimidad a su praxis.

\footnotetext{
${ }^{14}$ Esquivel, “Aportes” (nota 12), p.3.

15 Ibidem.

${ }^{16}$ Bonnin, "Discurso" (nota 5), p. 35-36.
} 
Fueron convocados por el Internacional Fellowship of Reconciliation, por Pax Christi, por el Secretariado Latinoamericano de Cáritas y por el Servicio de Paz y Justicia (de orientación no violenta). A su vez, la convocatoria se encolumnaba bajo el lema elegido por el Papa Pablo VI para la Jornada de Paz, "no a la violencia, sí a la paz". Con ese espíritu el documento retomaba tanto las elaboraciones previas del Comité Permanente del episcopado chileno, Evangelio y Paz (5/7/1975) como las del episcopado brasileño Las exigencias cristianas de un orden político (17/02/1977). El primero, denunciaba dos tipos de violencia, la revolucionaria y la contrarrevolucionaria, igualmente repudiables. El segundo, era una explicita condena a los llamados regímenes de seguridad nacional, que luego sería retomado en Puebla (1979).

Sobre estas bases la apuesta central del documento era ya no tanto la legitimación de la acción en sí misma, la transformación de la violencia institucional injusta, que había sido uno de los objetos centrales de la discusión durante la II CELAM en Medellín; sino la importancia de considerar las consecuencias de la acción y buscar alternativas viables atentas a ellas,

\begin{abstract}
"Ante la realidad de la no violencia existen varias respuestas. Unos prefieren ignorarla, no viéndola, prescindiendo de ella [...] refugiándose en el mundo ficticio, estrecho y cerrado de la propia clase social y del mundo que los rodea. Otros, sin ignorar la violencia, la consideran como inevitable, con actitud fatalista, o incluso necesaria como mal menor [...] Entre quienes sufren y son víctimas de la violencia, ésta produce pasividad, resignación y miedo [...] Otros por el contrario, se sienten llamados a la rebelión y a la lucha. No aceptan el mundo de las injusticias actuales. Sueñan con una sociedad más justa. Pero piensan que la realización de la utopía no se puede hacer sin recurrir a la violencia. Conscientes de la existencia de "situaciones cuya injusticia clama el cielo" tienen "la tentación de rechazar con la violencia tan graves injurias contra la dignidad humana" (Populorum Progressio, 30). Pero las tácticas de la contra-violencia han conducido a mayores penurias y a una represión todavía más implacable y opresora [...] La no violencia se nos presentó en este encuentro como una gran oportunidad ofrecida hoy a los cristianos, así como a todos los hombres y mujeres de buena voluntad, para actuar a favor de una sociedad cuya meta sea la superación de las dominaciones de todo tipo". ${ }^{17}$
\end{abstract}

De esta manera, el documento dio legitimidad eclesiástica a la demanda de los cristianos no violentos. La consagración de la alternativa de la no-violencia tuvo lugar a partir de su incorporación en la III Conferencia General del Episcopado Latinoamericano, reunida en Puebla (México), en 1979, cuando

${ }^{17}$ Documento Final del Encuentro Internacional de Obispos de América Latina sobre "La no violencia, fuerza de liberación” 1977 en Esquivel, Lucha (nota 9), p. 138-139. 
"Uno de los fundadores de este movimiento, el obispo Enrique Alvear, lograría que este criterio quedara aceptado en el artículo 533 de la Conferencia Episcopal de Puebla". ${ }^{18}$

A partir de entonces, los Documentos Finales de Puebla, que para buena parte de los teólogos de la liberación cristalizó su derrota político-religiosa respecto de Medellín ${ }^{19}$ se convirtió en una cita de autoridad recurrida para los no-violentos. ${ }^{20}$

En lo inmediato, el documento de Bogotá, de 1977, dio impulso a la creación de filiales nacionales del SERPAJ como sucedió en Chile. Al mismo tiempo sentó las bases para la acción de diversos grupos que hicieron suya la consigna de la no violencia en los años ochenta. Dado este impulso, lo que sin embargo determinó la creación de las filiales del SERPAJ en Chile y en Argentina fue la urgencia de hacer frente a la represión estatal contra el propio organismo.

Estos cambios, trajeron aparejado un proceso de reestructuración. El III Encuentro Continental, realizado también en Bogotá, en febrero de 1978, dio lugar a la creación de regionales. La región Cono Sur integró las filiales de Argentina, Chile, Brasil, Paraguay e Uruguay; la región Andina reunió a Colombia, Bolivia, Ecuador y Perú y, por último, la región de Centroamérica y el Caribe articuló las seccionales de México, Costa Rica, Guatemala, Honduras, Panamá, Nicaragua, Puerto Rico y Venezuela. En 1979, durante el IV Encuentro Continental, realizado en Riobamba (Ecuador) la consolidación de las seccionales nacionales y regionales planteó la necesidad de una reestructuración de la coordinación. Se ampliaron las funciones de dirección: Peréz Esquivel pasó a ser Coordinador General; Creuza Maciel, referente brasileña, asumió como Secretaria Ejecutiva y, más tarde, el sacerdote uruguayo, Luis Pérez Aguirre, se incorporó como asesor. A estos cambios se sumó, en 1980, la creación del Consejo Colegiado, el cual configuró una instancia de participación y decisión de los coordinadores de las secciones nacionales. Este proceso de descentralización de coronó en 1983 con el traslado de la Secretaría Ejecutiva del SERPAJ - AL, que pasó de Buenos Aires a Río de Janeiro, y con la fundación del SERPAJ-EUROPA, cuya cabeza visible fue desde entonces el pastor metodista Joke Schravesande.

${ }_{18}$ Rojas, "No-violencia" (nota 10), p. 3.

${ }^{19}$ Bonnin, "Discurso" (nota 5), p 8.

${ }^{20}$ Las referencias abundan, a modo de ejemplo véase: Paz y Justicia 10:82 (1982), p. 23; “Ayuno y oración": Paz y Justicia 1:2 (1983) p. 6; "Ética cristiana y elecciones": Paz y Justicia 1:5 (1983), p. 3. 


\section{Los movimientos de no violencia en los contextos nacionales}

Desde mediados de los años setenta, existían antecedentes de trabajo conjunto entre chilenos simpatizantes del SERPAJ e integrantes del Servicio instalado en Buenos Aires, fundamentalmente en torno a la problemática de los exiliados chilenos en Argentina. Sin embargo, la constitución formal de la filial chilena ocurrió recién en noviembre de 1977, cuando la detención de Adolfo Pérez Esquivel por el régimen militar dejó sin cabeza visible al SERPAJ América Latina. La necesidad de hacer frente al acontecimiento represivo, en un contexto de condiciones favorables, dadas por el respaldo de las iglesias cristianas y movimientos de paz europeos y el aval eclesiástico logrado a partir del documento de los obispos latinoamericanos en Bogotá, precipitó la creación del SERPAJ-Chile. ${ }^{21}$ El organismo comenzó a funcionar en una iglesia católica y consiguió su personería jurídica en 1979. Así quedó constituido en su grupo original por Jorge Osorio, Domingo Namuncura, Patricio Pietropaolo y Fernando Aliaga. Ese mismo año, tras la liberación de Pérez Esquivel, se decidió crear oficialmente la filial SERPAJ Buenos Aires, que quedó a cargo de su hijo, Leonardo Pérez Esquivel, mientras que Adolfo siguió a cargo de la coordinación general.

Este proceso de descentralización del organismo latinoamericano sucedía, a su vez, en una coyuntura de amenaza de conflicto bélico entre ambos países por la disputa en torno al canal de Beagle. El clima bélico fomentado desde 1977 había llegado a su clímax en la Navidad de 1978, cuando se concretó la mediación papal de Juan Pablo II a favor de la paz. En Chile, el conflicto significó una prueba de fuego para el SERPAJ. Contrariando el decreto-ley que prohibía las reuniones de estudio masivas bajo Estado de sitio, Claudio Orrego Vicuña organizó una serie de seminarios de reflexión, denominados "Jornadas de Paz". Al mismo tiempo, llevaron adelante sus primeras acciones contestatarias de agitación pública. Salieron a la calle a rechazar la guerra externa con Argentina y a denunciar la "guerra interna" impuesta por el gobierno militar. Estos actos de no violencia permitieron construir un origen legítimo a la filial chilena.

"En ese último trimestre del 78 se producía el roce con Argentina sobre el canal de Beagle y soplaron fuertes rumores de guerra, lo cual motivó a muchas intervenciones de obispos argentinos y chilenos, junto a la carta de Juan Pablo I y la misión encomendada al cardenal Samoré y la movilización de organismos por la paz [...] el Servicio de Paz y Justicia, etc., celebraron una jornada por la paz el 7-8 de Octubre.

${ }^{21}$ El protagonismo de los obispos chilenos en Bogotá es digno de destacar. Una delegación de cinco obispos participó de dicho encuentro: Enrique Alvear, Fernando Ariztía, Carlos Camus, Jorge Hourton y Alejandro Jiménez. Aliaga Rojas, “No-violencia” (nota 10), p. 12. 
Me invitaron a participar con Claudio Orrego, con los argentinos Augusto Fernández (luterano), Jorge Pascale (Serpaj) a un panel en el que expuse un “¡Basta ya!” una nueva denuncia a los abusos de la policía política. Conté la detención y torturas infligidas a 6 jóvenes de la Población La Pincoya". ${ }^{22}$

El obispo Jorge Hourton había sido uno de los cinco obispos chilenos que había participado del encuentro de Bogotá, de 1977, del cual resultó el documento "La no violencia evangélica, fuerza de liberación". Luego de aquella experiencia Hourton, junto con el obispo Enrique Alvear, fueron activos promotores de la fundación del SERPAJ Chile. ${ }^{23}$

La filial argentina, creada tras la acefalía dejada por la detención de Adolfo Pérez Esquivel, ganó en la práctica poca autonomía del secretariado latinoamericano. Adolfo Pérez Esquivel, una vez liberado, se sumó a las intervenciones de Augusto Fernández y Jorge Pascale por la "cuestión Beagle" e hizo suya la causa de la paz:

“Al igual que en la Navidad de 1978, los argentinos volvimos a sentir el peligro de la guerra con nuestros hermanos chilenos cuando festejábamos el 25 de Mayo. Las FFAA admiten hoy que ese día hubo un 'alerta rojo'. No podemos dejar de mencionar aquí que Adolfo Pérez Esquivel y el Servicio de Paz y Justicia denunciaron la posibilidad de esta aberrante "solución" al conflicto del Beagle hace ya varios meses". ${ }^{24}$

Si la represión estatal daba al organismo, razones institucionales para la descentralización, la amenaza de conflicto bélico entre ambos países generaba condiciones ideales en estos ámbitos nacionales para la recepción local de un organismo, como el SERPAJ, que en su mismo nombre llevaba impresa la bandera de la Paz.

Aunque en principio, existían elementos para pensar que la acogida de la no violencia tendría mayor receptividad en Chile, donde existía un imaginario nacional de "república democrática", que contrastaba con el sistema político pretoriano argentino de alternancia naturalizada entre civiles y militares; lo cierto es que de ambos lados de la cordillera fue la centralidad política que adquirieron las experiencias de violencia física, sumada a la hipótesis de conflicto bélico, lo que facilitó la acogida local.

En efecto, en el caso chileno, el imaginario de "cultura democrática" entraba en tensión con la misma historia política del país, que había dado lugar a diversos movimientos antipartidistas a lo largo del siglo XX.

${ }_{22}$ Jorge Hourton, Memorias de un obispo sobreviviente. Episcopado y dictadura (Santiago de Chile 2009), p. 274.

${ }^{23}$ Rojas, "No-violencia" (nota 10), p. 12-13.

24 "Inventar al enemigo": Paz y Justicia 1:2 (1983), p. 14. 
Incluso, se revelaba incongruente con las propias trayectorias político-biográficas de los referentes chilenos de la no violencia. Tal era el caso, por ejemplo, de Claudio Orrego Vicuña, uno de los principales organizadores de las Jornadas de Paz en torno la cuestión Beagle. En efecto, Orrego Vicuña era un militante de la democracia cristiana, que había sido funcionario del gobierno de Frei Montalva y acérrimo opositor del gobierno de Salvador Allende que lo sucedió. Era además un intelectual, formado en ciencias sociales en la Universidad de Lovaina (Bélgica) y autor de numerosas obras, entre ellas, Para una paz estable entre los chilenos (1974) y Manifiesto por la paz y la no violencia (1978). Según Fernando Aliaga Rojas, habría sido la experiencia propia de la represión estatal la que decidió su pasaje de asesor de los militares a franco denunciador del régimen militar. ${ }^{25}$ Al mismo tiempo, la filial chilena surgía, tal como señalamos, más de la necesidad que de la virtud, como respuesta a la detención de Adolfo Pérez Esquivel, entonces secretario latinoamericano.

En el caso argentino, donde las intervenciones militares en la vida política habían sido una constante durante el siglo $\mathrm{XX}^{26}$, al calor de las cuales se había acrecentado la legitimidad de la "violencia revolucionaria"27; fue el reconocimiento internacional de la no violencia, a través del otorgamiento del Premio Nobel de la Paz a Adolfo Pérez Esquivel, lo que dio visibilidad y mayor protagonismo al SERPAJ en el plano nacional.

"Cuando el 13 de Octubre de 1980, la noticia llegó a los teletipos: El Premio Nobel de la Paz de 1980 ha sido concedido a Adolfo Pérez Esquivel, causó una gran conmoción en los periódicos. ¿Quién era este hombre? ¿Dónde encontrar más datos sobre él? Fue necesario reconocer la evidencia: Adolfo Pérez Esquivel era un desconocido en los medios de comunicación social [...] Un periódico noruego comenzó por atribuirle nacionalidad brasileña [...] Una radio argentina lanzó la hipótesis de una nacionalidad paraguaya. Finalmente se aclaró todo: Adolfo Pérez Esquivel era argentino. Tenía la particularidad de ser discípulo de Gandhi. Un no violento". ${ }^{28}$

"Eso nos desordenó todo el trabajo - dice algo en broma Leonardo - [...] Ya lo habían nominado tres veces y creíamos que no se lo iban a dar, pero desde su detención por la dictadura, veíamos el tema de su nominación como una forma de protegerlo de nuevas agresiones. Digo que nos desordenó porque, a partir de allí, lo que

${ }^{25}$ Rojas, "No-violencia" (nota 10), p. 14.

${ }^{26}$ Cfr. Horacio Quiroga, El tiempo del "Proceso". Conflictos y coincidencias entre politicos y militares 1976-1983 (Santa Fe 2004). 2009).

${ }^{27}$ Hugo Vezzetti, Sobre la violencia revolucionaria. Memorias y olvidos (Buenos Aires

${ }^{28}$ Charles Antoine, "Prólogo": Pérez Esquivel, Lucha (nota 9), p. 7. 
habíamos planificado en el trabajo no sirvió más, la responsabilidad se hizo mucho más grande porque la gente visualizó a Adolfo y al Serpaj como referentes importantes en la lucha contra la dictadura y al mismo tiempo se empezó a acercar a nosotros". 29

La denuncia de estas realidades hizo posible la convergencia de derroteros ideológicos y prácticos, irreconciliables en el pasado, unidos en torno a una apelación práctica y emotiva "la no violencia", que solo con el tiempo ganaría contenido ideológico.

A comienzos de los años ochenta, bajo dictaduras militares, ambas filiales del SERPAJ se convirtieron en actores centrales en el proceso de impugnación de esos regímenes y reclamo por la vuelta a la democrática. Las filiales locales acompañaron el surgimiento y/o fortalecimiento de líderes y organizaciones que ganaron luego un peso propio como Madres de Plaza de Mayo en la Argentina y el Movimiento Contra la Tortura Sebastián Acevedo en Chile. Al mismo tiempo, el reconocimiento internacional de la consigna de la no violencia activa permitió reconvertir las estrategias hasta entonces puramente defensivas instrumentadas por los distintos organismos de derechos humanos, creados para atender las experiencias de sufrimiento de las víctimas, familiares y allegados de la violencia física impartida desde el accionar represivo del Estado. Las filiales locales participaron activamente en el impulso de instancias de movilización colectiva que permitieron articular a diversos actores que se oponían, sin conformar un frente de resistencia, a las dictaduras. Lentamente, estas instancias colectivas facilitaron la confluencia y fueron configurando un frente opositor.

“El Serpaj acompañaba las rondas de las Madres de Plaza de Mayo y realizaba jornadas y encuentros con ellas y otros familiares, sobre no violencia activa y otras formas de plantear sus luchas [...] Al mismo tiempo, mantenían el desarrollo de los grupos de base y acompañaron la toma de tierras en Quilmes [...] El actual dirigente de la Federación de Tierra y Vivienda, Luis D' Elía, participaba en las actividades barriales del SERPAJ. En otro frente, apoyaban a las agrupaciones combativas que intentaban recuperar sus gremios y en esas reuniones participaba Víctor de Gennaro, el actual titular de la Central de Trabajadores Argentinos (CTA) y su compañero Germán Abdala, que desde su agrupación ANUSATE intentaban recuperar ATE". 30

Estos liderazgos y activismos diversos confluyeron, luego, en movilizaciones masivas: La Marcha por la Vida, en 1982, la Marcha por el Pueblo y la

\footnotetext{
${ }^{29}$ Esquivel, "Aportes" (nota 12), p. 6-7.

${ }^{30}$ Esquivel, "Aportes" (nota 12), p. 7-8.
} 
Semana del Detenido-Desaparecido en 1983 fueron algunos hitos memorables en la Argentina. En el caso chileno, en el marco de la protesta nacional impulsada por los trabajadores del cobre en 1983, y de la represión militar que tuvo como respuesta inmediata, el SERPAJ conformó un Comité Creativo para difundir la metodología no violenta e innovar en el repertorio de protesta.

"La propuesta de la no violencia, que en estas circunstancias plantea el Serpaj, fue la convocación y funcionamiento del Comité creativo, integrado por dirigentes sociales, políticos y de las poblaciones más activas [...] Surgió así la idea de crear en cada población un espacio geográfico que se constituyera como "Zona de Libertad". A partir de una hora y día indicado, ese espacio geográfico se declaraba libre de la dictadura, construía barricadas y dentro de un estilo no violento realizaba diversas acciones impactantes". 31

A mediados de los ochenta, el recrudecimiento del accionar represivo frente al fallido atentado a Pinochet y el descubrimiento de armas en Carrizal Bajo había paralizado a buena parte de la oposición. Con el horizonte del Plebiscito de 1988, el SERPAJ organizó los llamados Talleres de Control del Miedo para fortalecer la oposición al régimen.

"La Sede del Serpaj se constituyó entonces en un lugar de encuentros abiertamente políticos. El tema principal era que mucha gente, siendo opositores al Régimen de Pinochet, por miedo a que se supiera el contenido de su voto y luego tener que sufrir las consecuencias, votaría a favor de la Dictadura. Fue así como surgió la idea de implementar los 'Talleres de Control del Miedo'”. 32

El mayor éxito, sin duda, fue la generalización de la estrategia no violenta propiciada por estos organismos desde los tempranos años sesenta. En los resquicios de la legalidad punitiva del Estado de Sitio se conformó un repertorio de protesta innovador y que persistiría en el tiempo: las rondas en Plaza de Mayo, el atraso automovilístico, el canto, los cacerolazos en Santiago, el ayuno. Estas estrategias, legales, de resistencia, contribuyeron a erosionar la legitimidad de dictaduras que no encontraban mejor respuesta que la prohibición, la represión y la censura. ${ }^{33}$

${ }^{31}$ Rojas, "No-violencia" (nota 10), p. 22-23.

${ }^{32}$ Ibidem, p. 24.

${ }^{33}$ Simultáneamente a la conformación de este repertorio, se volvieron audibles otras lecturas de los Documentos Finales de Medellín. Elaboraciones teológicas como las de Ronaldo Muñoz, tomaban elementos ya esbozados en el Documento de Paz de Medellín, para enfatizar que no toda insurrección violenta era legítima. Y si lo era, no era por ello, necesariamente, viable y socialmente responsable. Estas lecturas, difundidas en el Boletín del SERPAJ-AL fueron a su vez hechas públicas en declaraciones del obispo chileno Jorge Hour- 
"Fue en nuestro grupo de base, de reflexión cristiana, que surgió la necesidad de hacer algo. Nos conmovía el desamparo de las víctimas; nos indignaba lo inhumano de esta práctica hecha ley en Chile. Convocamos a nuestros amigos y salimos a la calle a denunciar, frente al cuartel secreto de la CNI, "Aquí se tortura". Luego entre las columnas del Palacio de Justicia extendimos nuestro lienzo que decía "Se tortura en Chile y la justicia es cómplice". Frente al diario oficialista, El Mercurio, recitamos una lista de cargos: ¡tantas torturas! y "El Mercurio calla". Hasta que llegó la policía a disolvernos con violencia". ${ }^{34}$

\section{Revolución, sufrimiento y democracia}

Como vimos, la consigna de la no violencia llegó a América Latina como parte de un movimiento internacional que propiciaba una alternativa revolucionaria. Sin embargo, caló hondo en América Latina a partir de las experiencias de violencia física (tortura, asesinatos, desaparición, cárcel y exilio) practicadas por el terrorismo de Estado, durante las dictaduras. El repertorio de protesta propiciado por la estrategia no violenta no sólo cuestionaba la legitimidad de los regímenes militares desde los resquicios de la legalidad punitiva del Estado de Sitio, sino que convocaba a la protesta, no tras la bandera de la revolución, sino como forma activa de procesar el sufrimiento político.

"A semejanza de Cristo, el no violento trata de vivir la espiritualidad del siervo
sufriente (Isaías, 53); evita todo espíritu de dominación sobre las personas, elimina
todos los signos de discriminación o superioridad. Busca serenidad por el entrena-
miento continuo para vencer el miedo. Vive la verdad pero siempre con amor"35

Así, también, lo expresa Adolfo Pérez Esquivel en su discurso pronunciado en Oslo, al recibir el Premio Nobel de la Paz:

"Quiero como los Obispos en Puebla, como los cristianos comprometidos en los movimientos que luchan por los derechos humanos, como los hombres de buena voluntad, compartir las angustias que brotan de los rostros dolientes del hombre

ton y del mismo Adolfo Pérez Esquivel. Cfr. Rolando Muñoz, "Una visión cristiana en la perspectiva de los pobres. Violencia y protesta en Chile" Paz y Justicia 1:3 (1983), pp. 42-44. Para una interpretación sobre el Documento de Paz, de Medellín, Cfr. Bonnin, "Discurso" (nota 6) pp. 130-161.

${ }^{34}$ José Aldunate, "Nuestra acción en Chile por los derechos del hombre": Páginas 13:91 (1988), p. 84.

${ }^{35}$ Documento final del Encuentro Internacional de Obispos de América Latina sobre "La no violencia, fuerza de Liberación”, en Esquivel, Lucha (nota 9), p. 141. 
latinoamericano, en el que reconocemos el rostro sufriente de Cristo, nuestro Señor, que nos cuestiona e interpela". ${ }^{36}$

No se trataba, sin embargo, de una mera interpelación a la compasión, o a la conmiseración, sino que tomando como discurso modélico, la apelación del profeta Isaías, se buscaba impulsar la denuncia: transformar el sufrimiento de los violentados en un "sufrimiento liberador. En esta clave, la asociación entre liberación y revolución, consagrada en los años sesenta, era desplazada (sin por ello desaparecer) por la de liberación y sufrimiento. Esto suponía una metodología que transformaba primero al sujeto para luego denunciar el orden político. Para ello, proponía un ejercicio ascético, es decir, una sistematización de la conducta (cuerpo y mente) a través del ayuno y la oración para, luego, convocar a la desobediencia civil.

\footnotetext{
"Y se quejan: ‘¿Por qué ayunamos y tú no lo ves; nos humillamos y tú no lo tomas en cuenta? [...] 'No saben cuál es el ayuno que me agrada? Romper las cadenas injustas, desatar las amarras del yugo, dejar libres a los oprimidos, y romper toda clase de yugo (Isaías 58)" ${ }^{37}$

"El 'Servicio de Paz y Justicia' indica tres etapas en la acción no violenta: 1) descubrir la injusticia e indicarla directamente al responsable; 2) si el diálogo no resulta eficaz, poner en marcha a las masas con hambre pública y persuasión de la opinión. Evitar acción espontánea, sinónimo de fracaso; 3) si no se dan cambios, apelar a la desobediencia civil". ${ }^{38}$
}

En la práctica, imposibilitado el diálogo con los funcionarios de los gobiernos militares, se puso en práctica un repertorio de intervenciones públicas que combinaban de manera particular ascesis y emoción. En Chile, el Movimiento contra la Tortura Sebastián Acevedo, formado con asesoramiento técnico del SERPAJ Chile, reconoce sus antecedentes en la huelga de hambre de los familiares de detenidos-desaparecidos, realizada entre mayo y junio de 1978, y acompañada por la Vicaría de la Solidaridad. Allí el sacerdote José Aldunate, quien sería uno de los fundadores del MCTSA, comenzó a formular un contenido emotivo que, con el tiempo, ganaría radicalidad:

${ }^{36}$ Adolfo Pérez Esquivel, Discurso en Oslo al recibir el Premio Nobel de la Paz, Oslo, 10 de diciembre de 1980, en Esquivel, Lucha (nota 9), p. 155.

37 “Ayuno y Oración”: Paz y Justicia 1:2 (1983), p. 8.

${ }^{38}$ Esquivel, Lucha (nota 9), p. 41. La cursiva es nuestra. 
"Solidarizar con la víctima no es solamente cubrir sus heridas, sino abrazar con ella o en nombre de ella un proyecto liberador". ${ }^{39}$

“En los años ochenta, la idea-fuerza del 'amor por los cuerpos torturados' se convertirá en un sello identitario del MCTSA". ${ }^{40}$

Esta apelación emotiva encontró fundamento en la reconversión de amas de casa, madres, padres y familiares en actores políticos, que hicieron de la familia desgarrada, el centro de la denuncia política a los regímenes militares. ${ }^{41}$ En este punto el SERPAJ-Argentina tendrá un rol central en el acompañamiento y la constitución como grupo de quienes fueron entonces bautizadas por Pérez Esquivel como "madres del coraje" y más tarde fueron mundialmente reconocidas como Madres de Plaza de Mayo:

"En las semanas que siguieron al golpe de Estado del general Videla, en Marzo de 1976, madres afligidas, cada vez más numerosas, acudieron al pequeño equipo de Servicio de Paz y Justicia en Buenos Aires [...] Con el apoyo del Servicio de Paz y Justicia, las madres se animaron mutuamente para tratar de superar su desesperación. Hasta el día que nació la idea no violenta de manifestarse en silencio en Plaza de Mayo, en el centro de Buenos Aires, hasta que obtengan respuesta de las autoridades [...] La obstinación del amor maternal apelando desesperadamente a lo que puede quedar de la sensibilidad humana el corazón de un déspota. El coraje de mujeres sin defensa". ${ }^{42}$

El MCTSA, por su parte, tomó su nombre, Sebastián Acevedo, en homenaje a un padre de dos hijos torturados que, sumido en la desesperación, se inmoló frente a la Catedral de Concepción. En este caso, la apelación emotiva no solo se plasmó en el nombre del movimiento, sino que se integró al repertorio ascético típico de los no violentos. Es decir, la huelga de hambre y la oración se acompañaba de todo un repertorio de acciones teatrales que buscan interpelar a los conciudadanos y a la opinión pública.

${ }^{39}$ José Aldunate, "Sondeando un mensaje. La vicaría de la solidaridad": Mensaje 16/04/79, p. 1, en línea: http://www.archivovicaria.cl/archivos/VS0000101.pdf [02-02-2015].

${ }^{40}$ Aldunate, "Acción" (nota 34), p. 85.

${ }^{41}$ Cfr. Judith Filc, Entre el parentesco y la politica. Familia y dictadura. 1976-1983 (Buenos Aires 1997).

${ }^{42}$ Esquivel, Lucha (nota 9), p. 52. Buen ejemplo de la estrechez del vínculo construido entre el SERPAJ y Madres de Plaza de Mayo será la donación que hará Mercedes Lagrava de Martínez, "Mamá Mercedes", al SERPAJ, legándole su propia casa para sede de funcionamiento del organismo. Cfr. Patricia Funes, "La política y lo político entre la dictadura y la democracia. Un estudio de caso: redes trasnacionales, biografía, archivo y memoria", Taller Internacional Las formas de lo político en América Latina y Europa. Lógicas nacionales y trasnacionales, Instituto Gino Germani, (Buenos Aires 6 y 7 de agosto de 2013). 
"Por 'acciones' entendemos actividades colectivas de denuncia que nos sacaban a las calles y lugares públicos. La mayoría se reunía bajo un lienzo y con nuestro canto: 'Por el pájaro enjaulado ...' y los otros gestos característicos de nuestra liturgia. La demás acciones eran muy variadas. La mayoría eran muy breves: 5 o 7 minutos que se cumplían a cabalidad, estuviera o no la policía [...] Las acciones públicas que nos sacaron a la calle fueron unos 180 en los 6 años y medio que actuó el Movimiento". ${ }^{43}$

En esta dinámica de la acción, la misma experiencia represiva se convirtió en acción de protesta. Por una parte, la provocación del "hecho policial" era buscada como una estrategia de repercusión pública. A medida que se fortalecía la estrategia no violenta, no se temía ir contra las leyes del Estado de Sitio y apelar a la desobediencia civil, amparados en el impacto internacional. Por otra parte, la experiencia de cárcel era vivida como una escuela de militancia.

"La acción tuvo 5 gestos que caracterizarían nuestros operativos: el lienzo colocado sobre el portón, la denuncia verbal, el canto, la detención del tráfico y la espera de la policía que detendría a algunos (no pudiendo detener a todos). Así se provocaba el 'hecho policial' que saldría en algunos medios de publicidad y al menos en noticieros extranjeros. Periodistas amigos eran convocados para filmar las acciones y así se conservaban en detalle en videos las denuncias y las represiones policiales". ${ }^{44}$

"No tememos a la detención. Cuando se detiene a uno, no faltan voluntarios que lo acompañan. La detención es noticia y la noticia se traduce en concientización" ${ }^{45}$

Las detenciones y torturas sufridas por distintos militantes del SERPAJ, incluso por el mismo Adolfo Pérez Esquivel, fueron experimentadas como una profundización del compromiso con los violentados y con la alternativa de la no violencia activa:

"Reciban mis afectuosos saludos desde este lugar de detención forzosa. Me siento fortalecido en el Señor y en la no violencia que antes de la prisión (sic). Doy gracias que estoy compartiendo el dolor con los pobres y oprimidos del Continente. Sé que mis familiares, amigos y compañeros están apoyando mis sufrimientos y confío en que estas horas amargas darán fecundos frutos de liberación". ${ }^{46}$

\footnotetext{
${ }^{43}$ Aldunate, "Movimiento" (nota 7) p. 11-12.

${ }^{44}$ Ibidem, p. 11.

${ }^{45}$ José Aldunate, "Movimiento" (nota 7), p. 100.

${ }^{46}$ Jorge Osorio Vargas, "Servicio de Paz y Justicia, Chile": Paz y Justicia 10:82 (1982).
} 
"Fui arrestado el primer día de Semana Santa, el 4 de abril. También era el aniversario de la muerte de Martin Luther King. Ciertamente viví esa Semana Santa de manera muy especial. Durante los dos primeros días del 'tubo', permanecí en la oscuridad más completa. El tercer día, cuando los vigilantes abrieron la puerta, entró la luz y pude leer innumerables inscripciones, nombres de seres queridos, oraciones, insultos [...] Pero lo que más me impresionó fue una enorme mancha con una inscripción escrita debajo con el dedo mojado en sangre. Leí "Dios no mata". Esta inscripción se quedó grabada en mi [...] Esto ocurría en medio de las torturas". ${ }^{47}$

El primer fragmento, escrito por uno de los referentes del SERPAJ Chile, desde la cárcel refuerza la idea que venimos desarrollando, la apelación a un "sufrimiento liberador" a partir de la denuncia no violenta. El segundo, perteneciente a Adolfo Pérez Esquivel, secretario latinoamericano del SERPAJ, expresa la construcción de un linaje que condensa la pasión de Cristo con el martirio de Martin Luther King, quien junto a Gandhi se convertirá en uno de los referentes internacionales de la no violencia activa. Al mismo tiempo, encuentra el la misma experiencia de cárcel, el leit-motiv de su acción, "Dios no mata", que, reformulado como la sacralización del derecho a la vida, se convertirá en la principal fuente de la impugnación a las dictaduras y del fundamento ético de las democracias.

En la Argentina, el 5 de Octubre de 1982 tuvo lugar en la Argentina la llamada Marcha por la Vida, convocada por ocho organizaciones de derechos humanos, entre ellos el SERPAJ. La marcha convocó a más de 10.000 personas, a pesar del despliegue represivo y la prohibición del gobierno difundida por radio y televisión. Los manifestantes reclamaron por

"la aparición con vida de los detenidos-desaparecidos; especialmente los niños; por la libertad de todos los presos políticos y gremiales; el levantamiento del estado de sitio y por el desmantelamiento del aparato represivo". ${ }^{48}$

Con ocasión del acontecimiento el SERPAJ, concluyó en su revista Paz y Justicia:

"El tema de los desaparecidos dejó ya de pertenecer al mero campo político, para convertirse en un planteo ético-moral al que los implicados deberán responder, asumiendo responsabilidades. Este esclarecimiento supone la instauración de una real democracia, una democracia participativa". ${ }^{49}$

\footnotetext{
${ }^{47}$ Esquivel, Lucha (nota 9), p. 28.

48 "Marcha por la vida. El nuevo protagonismo", Paz y Justicia 10:84 (1982), p. 17.

${ }^{49}$ Ibidem.
} 
En la misma sintonía, el 19 de mayo de 1983 se inició la Semana Internacional del Detenido-Desaparecido. En esa ocasión, el SERPAJ inició un “Ayuno y Oración" bajo el mandato evangélico 'No matarás':

\begin{abstract}
“Ayunamos por el derecho a la vida, al pan y a la libertad de nuestro pueblo. Ayunamos y oramos porque en el país no han aparecido con vida los detenidos-desaparecidos [...] Ayunamos y oramos porque aún no han sido puesto en libertad los presos por razones políticas y gremiales [...] Ayunamos porque aún los niños nacidos en cautiverio no han sido entregados y restituidos a sus familias [...] Ayunamos y oramos porque todavía no se ha dispuesto previo a las elecciones el levantamiento definitivo del estado de sitio [...] Por eso clamamos: basta de represión, porque no matarás la vida y la esperanza". ${ }^{50}$
\end{abstract}

Una vez consagrado el triunfo del radicalismo, el 30 de octubre de 1983, el SERPAJ desde su revista, hará una identidad propia de la generalización exitosa de la estrategia no violenta, que buscando transformar el sufrimiento (represivo) en liberación, facilitó la conformación de un frente de resistencia a la dictadura:

"Existen [...] múltiples experiencias de lucha no violenta que se han manifestado en la resistencia contra la dictadura. Son estas experiencias las que permitieron ir ganando espacios de participación y libertad. Los asentamientos de pobladores en tierras de la periferia de la ciudad de Buenos Aires (Quilmes) [...] Los ayunos de estudiantes en Córdoba y en Rosario, de los obreros de distintas empresas, de los empleados de varias instituciones, de los presos políticos, una nueva forma de lucha que se generalizó en los últimos tiempos. Los grupos y las comunidades de base en busca de solución a sus problemas fueron generando alternativas liberadoras y multiplicando las acciones con creatividad y decisión a pesar de la fuerte represión que sufrieron". ${ }^{51}$

En la misma coyuntura, en Chile, florecieron las llamadas protestas nacionales. Las protestas, iniciadas en torno a la Confederación General de Trabajadores del Cobre, fueron vividas por muchos como el "principio del fin" del régimen de Pinochet. ${ }^{52}$ En esa ocasión y, haciéndose eco de los acontecimientos del país vecino, proliferaron las reflexiones en torno a la democracia. En aquella ocasión el SERPAJ-Chile se manifestó:

"Cuatro protestas nacionales han significado para el pueblo de Chile el duro costo de 35 chilenos muertos, asesinados abiertamente por el despliegue represivo, cien-

\footnotetext{
50 “Ayuno y oración”: Paz y Justicia 1:2 (1983), p. 5.

51 "Democracia y no violencia": Paz y Justicia 1:1, s/d (1983) p. 18.

${ }^{52}$ Carlos Eichelbaum, "El principio del fin": Paz y Justicia" 1:5 (1983), p. 46.
} 
tos de heridos, miles de detenidos y otros tantos relegados. El pueblo de Chile ha recurrido a la protesta pacífica como una manera de hacer oír su voz. Han pasado ya 10 años y el pueblo está cansado de injusticia, del autoritarismo y de la miseria [...] Lo mínimo que los chilenos requerimos es libertad [...] Libertad para escoger democráticamente el gobierno que represente mejor las aspiraciones del pueblo chileno". 53

La respuesta represiva del régimen a las protestas nacionales puso en el centro de la escena el "derecho a la vida" como reclamo fundamental. En ese contexto, el arzobispado de Santiago de Chile, a través de la Vicaría de la Solidaridad impulsó una movilización de protesta contra el gobierno que se inició el 20 de junio de 1984 con la convocatoria a noventa agentes pastorales de distintas zonas de la arquidiócesis bajo el lema "Por el Derecho a la Vida". En esa oportunidad los equipos regionales del SERPAJ-Chile hicieron de cabeza en las provincias. El encuentro llamaba a la acción no violenta, a través de la organización de vigilias de oración, cartas de adhesión, campañas de alimento y peñas. Particularmente se pedía el apoyo al MCTSA y el fomento de comités de defensa de Derechos Humanos. Las demandas de los concurrentes incluían la organización de una campaña para la derogación de la Ley Antiterrorista y la disolución de la CNI. Estos llamados y sugerencias a la acción fueron sintetizados en el comunicado del Comité Permanente del Episcopado Chileno del 13 de julio con un "vehemente llamado a la comunidad nacional para que se respete y promueva la vida de los chilenos". A los pocos días se formó un Comité de Personalidades integrado por el entonces ex cardenal Raúl Silva Henríquez, el ex dirigente sindical Clotario Blest, el ex ministro demócrata cristiano Bernardo Leighton, el pintor Nemesio Antúnez, María Angélica Prats, hija del general Carlos Prats asesinado por los servicios de seguridad chilenos en Buenos Aires, y los académicos Héctor Croxato y Teresa Carvajal, quienes convocaron a una campaña nacional denominada "Chile defiende la Vida". Luego se formó una Campaña Nacional integrada por el plenario de organismos de derechos humanos, los tres conglomerados políticos (el Movimiento Democrático Popular, la Alianza Democrática y el Bloque Socialista) y la Iglesia Católica, a través de la Vicaría de la Solidaridad. El régimen autorizó las actividades públicas que culminarían con una jornada "Chile defiende la vida" el 9 de agosto, pero aprovechó la censura que impedía el acceso de la oposición a los medios de comunicación para desvirtuar la campaña.

\footnotetext{
53 “El pueblo quiere libertad": Paz y Justicia 1:5 (1983), p. 47.
} 
A pesar de ello, y de que la vuelta a la democracia se hizo esperar, desde el SERPAJ cobraron fuerza los Comités de Derechos Humanos, las Escuelas de No Violencias Activa, los Talleres de Control del Miedo y las Mesas de Análisis Político que, mediante a la convocatoria de distintos dirigentes políticos, colaboraron a preparar el camino para la Concertación de Partidos para la Democracia. El MCTA, que tenía tan solo un año de existencia, no descansó hasta ver consagrada la democracia en las urnas.

\footnotetext{
"Era el tiempo de las protestas. Se instalaron artefactos de tortura en todas las comisarías. La cosa era muy seria. Entonces el gobierno se volvía totalmente torturador. Dijimos esto hay que denunciarlo ante el país y el mundo. Armamos un grupo de denuncia de la tortura, que no usaba la violencia. Hacía protesta pacífica en las calles. Era el sistema Ghandi, es decir la no violencia activa. Activa sí, bien activa: tuvimos 180 salidas a la calle en siete años". ${ }^{54}$
}

\section{Conclusiones}

La consigna de la no-violencia formó parte de un movimiento internacional de cristianos y militantes de paz que tardó en calar hondo en la realidad latinoamericana. Su inscripción fue primero regional, bajo la forma de la conformación de una red, el SERPAJ, capaz de articular diversas experiencias existentes en el sub-continente y dar impulso a otras nuevas. El anclaje regional a fines de los años sesenta recién alcanzó su expresión nacional en Argentina y Chile una década después. En buena medida este letargo respondió a su propia condición. Se trató de una corriente social que nació en torno al consenso de un mandato ético "la no violencia activa", a contrapelo del clima epocal latinoamericano signado por la revolución por las armas. A pesar de los esfuerzos iniciales por encarnar una alternativa revolucionaria, no tuvo entonces el eco esperado y sólo encontró más tardíamente su objeto concreto con la denuncia de la violencia física implementada por el accionar represivo del Estado, bajo las dictaduras militares. Los no violentos aportaron entonces una metodología para procesar el sufrimiento y denunciar las violaciones a los derechos humanos, sin perder el horizonte liberacionista, declarado desde fines de los años sesenta. Para ello, se valieron de un repertorio de acciones que combinaban de manera particular una apelación emotiva y ascética eficaz para reconvertir en actores políticos a

${ }^{54}$ José Aldunate, "Construir el reino en la tierra bajo la luz de la eternidad": Historia activa (2012), p. 11, en línea: http://historiactiva.jesuitas.cl/2012/entrevista_33/j_aldunate. pdf [11-10-2013]. 
madres, padres y familiares que hicieron de la familia desgarrada su capital político de denuncia. De esta manera, los cristianos no violentos colaboraron a construir las democracias de la región sobre un terreno más afectivo que ideológico. Así fue como contribuyeron a instalar el mandato de "no matarás" (el derecho a la vida) en el corazón sagrado de las democracias actuales. 